Research Article

\title{
Electrochemical Reduction of Oxygen and Nitric Oxide on Mn-Based Perovskites with Different A-Site Cations
}

\author{
K. Kammer Hansen (iD \\ Department of Energy Conversion and Storage, Technical University of Denmark, DK-2800, Lyngby, Denmark \\ Correspondence should be addressed to K. Kammer Hansen; kkha@dtu.dk
}

Received 31 December 2019; Accepted 10 March 2020; Published 29 March 2020

Academic Editor: Adalgisa Rodrigues de Andrade

Copyright (c) 2020 K. Kammer Hansen. This is an open access article distributed under the Creative Commons Attribution License, which permits unrestricted use, distribution, and reproduction in any medium, provided the original work is properly cited.

Four $\mathrm{LnMnO}_{3+\delta}(\mathrm{Ln}=\mathrm{La}, \mathrm{Pr}, \mathrm{Sm}$, and Gd) perovskites were synthesized and characterized by powder XRD. It was shown that the perovskite lattice became more and more distorted when lowering the size of the A-site cation. The manganite-based perovskites were evaluated for the ability to electrochemically reduce oxygen and nitric oxide in the temperature range of 200 to $400^{\circ} \mathrm{C}$. At the lowest temperature, the electrodes were better at reducing nitric oxide than oxygen. At higher temperatures, the activity for the reduction of oxygen and nitric oxide became similar. The activation energies for the reduction of oxygen and nitric oxide were markedly different for $\mathrm{LaMnO}_{3+\delta}$ and $\mathrm{PrMnO}_{3+\delta}$ whereas it was similar for $\mathrm{SmMnO}_{3+\delta}$ and $\mathrm{GdMnO}_{3+\delta}$.

\section{Introduction}

Pollution from mobile and stationary sources is of still greater concern [1]. While the emissions of NOx from petrol-fired engines can be significantly lowered using the three-way catalytic converter [2], problems still remain for the cleanup of the exhaust from diesel-fired engines, due to excess oxygen in the exhaust gas [3]. The best known solution for the removal of nitrogen oxides from diesel engines is the selective catalytic reduction (SCR) with ammonia [4]. This solution requires, however, storage of the reducing agent on board the vehicle. There also exists the possibility of slip of the reducing agent.

An alternative solution to the SCR route is the reduction of the NOx in an all-solid-state electrochemical reactor, based on an oxide anion conductor, as suggested by Pancharatnam et al. [5]. In such a reactor, the NOx is reduced at the cathode to nitrogen and oxide anions. The oxide anions are then transported through the electrolyte to the anode where oxygen is formed. Obstacles still remaining for this solution are a low activity at the temperatures of the exhaust gas and a low selectivity due to simultaneous reduction of oxygen at the cathode, leading to high power consumption (see, e.g., [6] for a recent review).
Manganite-based perovskites have been investigated as cathodes for the electrochemical reduction of nitric oxide [7-9]. It has been shown that the manganite-based perovskites are active towards the reduction of nitric oxide even at the low temperature of a diesel exhaust gas.

In this study, manganite-based perovskites with different A-site cations are for the first time investigated for the reduction of oxygen and nitric oxide at the temperature interval of a real diesel exhaust gas. Manganite perovskitebased cathodes, with different A-site cations, have been studied before for the use as oxygen reduction cathodes $[10,11]$. In some cases, the effect is quite large. Especially, it has been tried to use different A-site cations in $\mathrm{Ln}_{0.6} \mathrm{Sr}_{0.4} \mathrm{MnO}_{3+\delta}$ and it was shown that the Pr-containing perovskite had the highest activity towards the reduction of oxygen at a temperature of $700^{\circ} \mathrm{C}$ [11]. No studies for the electrochemical reduction of nitric oxide on perovskites with different A-site cations have been reported in the open literature. The study is done on cone-shaped electrodes as suggested by Fabry and Kleitz [12]. The advantage of the cone-shaped electrodes is that the contact area is well defined and that the processing of the electrolyte and electrode is done separately, thereby avoiding reaction between the electrode and the electrolyte during sintering. 


\section{Experimental}

Synthesis of the manganite-based perovskites was done using the glycine-nitrate process [13]. In short solutions of the metal nitrates were mixed in a beaker in the appropriate ratio. Glycine was then added, and the solutions were heated on a hot plate until ignition. Then, the resulting powders were calcined in a box furnace in air at $1100^{\circ} \mathrm{C}$ for $12 \mathrm{~h}$. Phase purity of the as-synthesized powders was checked using powder X-ray diffraction. After this, pellets of the powders were made by pressing the powders in an appropriate die followed by sintering. Finally, diamond tools were used to shape the as-sintered pellets into cone-shaped electrodes. XRD was performed on the sintered pellets in order to be certain that the perovskite structure still was present after sintering at high temperatures.

The cone-shaped electrodes were tested in a pseudo-3electrode setup [14], with a Pt reference/counter electrode and a one end closed yttria stabilized zirconia tube (Vesuvius) (see Figure 1). The end, of the zirconia tube, exposed to the cone-shaped electrodes was polished down to $1 \mu \mathrm{m}$ with diamond paste. Approximately $60 \mathrm{~g}$ of weight was applied to the cone-shaped electrodes. The electrochemical measurements were done using a Gamry Femtostat potentiostat. The voltammograms were recorded between $0.4 \mathrm{~V}$ and $-0.8 \mathrm{~V}$ vs. air, starting at open circuit voltage $(\mathrm{OCV})$ and sweeping in the cathodic direction first. The voltammograms were recorded with sweep rates 1 or $10 \mathrm{mV} / \mathrm{s}$. Electrochemical impedance spectroscopy (EIS) was also recorded at OCV. The EIS was recorded from $300 \mathrm{kHz}$ to $50 \mathrm{mHz}$, with 10 points per decade. An amplitude of $25 \mathrm{mV}$ rms was used. The EIS was used to find the contact area of the cone-shaped electrodes using Newman's formula [15]. The electrochemical behavior of the manganite-based perovskites was tested in atmospheres containing either $10 \%$ oxygen in argon or $1 \%$ nitric oxide in argon. Brooks mass flow controllers were used to control the flow rate and gas composition. The flow rate was kept at $20 \mathrm{~mL} / \mathrm{min}$ throughout. The electrochemical measurements were done at 200,300 , and $400^{\circ} \mathrm{C}$.

\section{Results}

Results from the powder XRD diffraction show that the assintered perovskites are of single phase. The unit cell parameters can be found in Table 1. The lanthanum-containing manganite has a hexagonal structure, whereas the other manganites have an orthorhombic structure. The manganites become more and more distorted from the ideal cubic perovskite structure when lowering the ionic radii of the A-site cation.

Examples of voltammograms are given in Figures 2-7 (the results for the $\mathrm{LaMnO}^{+}+_{\delta}$ is taken from [9], but is plotted here again for clarity). In Figure 2, the results of the measurements in the oxygen-containing atmosphere at $200^{\circ} \mathrm{C}$ are shown. It is seen that the $\mathrm{LaMnO}_{3+} \delta$ and the $\mathrm{PrMnO}_{3+} \delta$ perovskites have an equal activity and that the $\mathrm{SmMnO}_{3+\delta}$ and $\mathrm{GdMnO}_{3+\delta}$ perovskites also have an equal activity, which is markedly higher than that for the

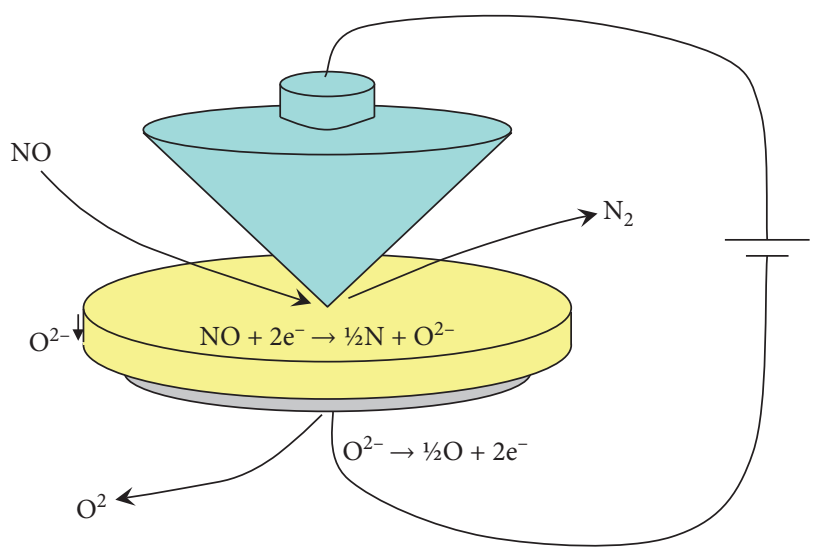

FIGURE 1: A sketch of a setup for measurements on cone-shaped electrodes. The setup is used for evaluating the ability of electrode materials to electrochemically reduce either oxygen (not shown) or nitric oxide. The setup is a pseudo-three-electrode setup as the size of the counter/reference is many times larger than that of the working electrode (the cone). It is seen that the nitric oxide is reduced to nitrogen and oxide anions, at the cone-shaped electrode. The setup is a two-atmosphere setup.

TABLE 1: The unit cell parameters for the four perovskites. It is seen that the unit cell becomes more and more distorted from the ideal cubic perovskite structure, when the size of the A-site cation is lowered.

\begin{tabular}{lcccc}
\hline Compound & $\mathrm{LaMnO}_{3+\delta}$ & $\mathrm{PrMnO}_{3+\delta}$ & $\mathrm{SmMnO}_{3+\delta}$ & $\mathrm{GdMnO}_{3+\delta}$ \\
\hline $\mathrm{A}(\AA)$ & 5.5197 & $7.635(6)$ & $7.4873(18)$ & $7.4344(15)$ \\
$\mathrm{B}(\AA)$ & 5.5197 & $5.604(3)$ & $5.8342(18)$ & $5.8680(19)$ \\
$\mathrm{C}(\AA)$ & 13.354 & $5.451(4)$ & $5.3606(15)$ & $5.3166(12)$ \\
Volume $\left(\AA^{3}\right)$ & 127.6 & 233.3 & 234.2 & 232.0
\end{tabular}

$\mathrm{LaMnO}_{3+\delta}$ and $\mathrm{PrMnO}_{3+\delta}$ perovskites. Again at $300^{\circ} \mathrm{C}$ (see Figure 3), the Sm- and Gd-containing perovskites have an almost identical activity. At this temperature, the La-containing perovskites have a much higher activity than the other perovskites, and the $\mathrm{PrMnO}_{3+\delta}$ perovskite has a much lower activity. At $400^{\circ} \mathrm{C}$ (Figure 4), the $\mathrm{PrMnO}_{3+\delta}$ perovskite again performs the worst. At potentials between 0 and $-0.7 \mathrm{~V}$ vs. air, the $\mathrm{LaMnO}_{3+\delta}$ still performs the best, when it comes to the reduction of oxygen. However, at low potentials, the downward bend of the voltammograms is stronger on the Sm- and Gd-based manganites than on the $\mathrm{LaMnO}_{3+\delta}$ perovskite, making them more active towards oxygen reduction at the very lowest applied potentials. The manganitebased perovskites are also able to oxidize the oxide ions to oxygen. The $\mathrm{PrMnO}_{3+\delta}$ perovskite is the most active in this sense.

In the nitric oxide-containing atmosphere, a markedly different behavior of the perovskites is observed (see Figures 5-7). At the lowest temperature $\left(200^{\circ} \mathrm{C}\right)$, the lanthanum-based manganite has a much higher activity than the other perovskites (see Figure 5). The magnitude of the current densities is markedly higher in the nitric oxidecontaining atmosphere than in the oxygen-containing atmosphere, at this temperature. As it is also observed in the oxygen-containing atmosphere, the differences between the 


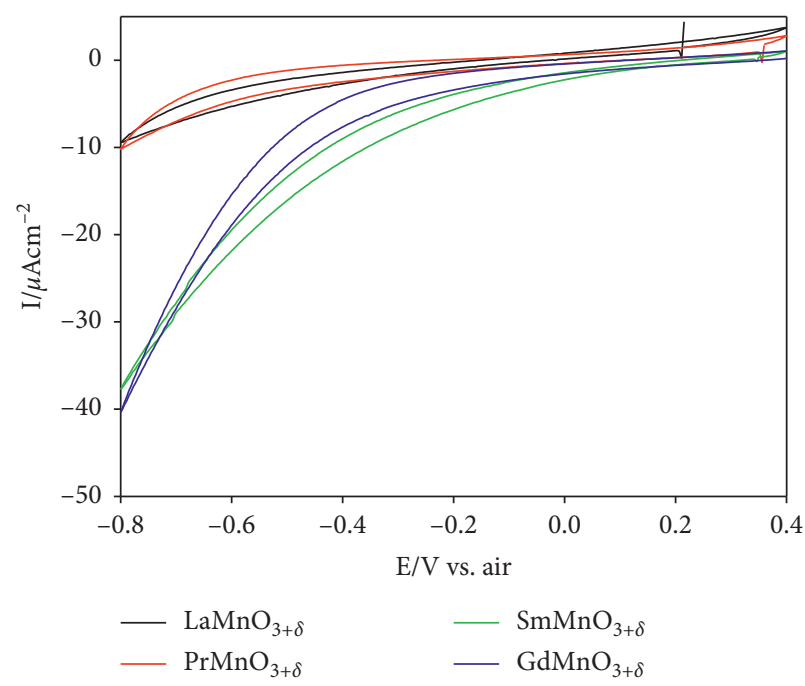

Figure 2: Voltammograms recorded in $10 \% \mathrm{O}_{2}$ in Ar at $200 \mathrm{C}$ with a sweep rate of $1 \mathrm{mV} / \mathrm{s}$. The voltammograms show that the materials are active for both oxygen evolution and oxygen reduction. A marked difference in the activity is observed as a function of A-site cation. The most active compounds are the $\mathrm{SmMnO}_{3+\delta}$ and $\mathrm{GdMnO}_{3+\delta}$ perovskites.

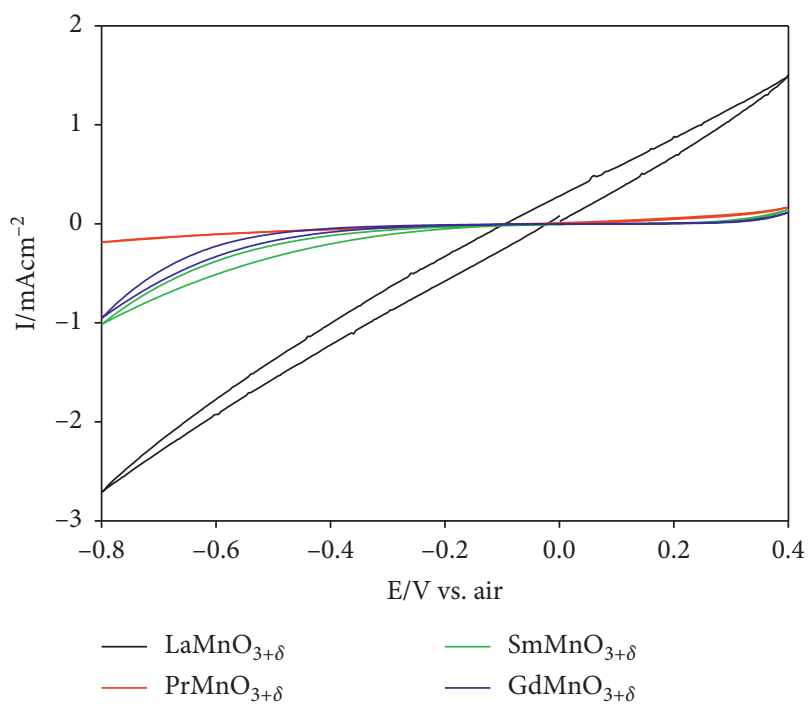

Figure 3: Four voltammograms recorded at $300 \mathrm{C}$ in $10 \% \mathrm{O}_{2}$ in $\mathrm{Ar}$ with a sweep rate of $1 \mathrm{mV} / \mathrm{s}$. Again a marked difference is seen as a function of the A-site cation. The $\mathrm{LaMnO}_{3+\delta}$ perovskite is the most active compound for both oxygen evolution and oxygen reduction, whereas the $\mathrm{PrMnO}_{3+\delta}$ perovskite is the one with the lowest activity.

activities of the perovskites level out at the higher temperatures (see Figures 6 and 7). At $400^{\circ} \mathrm{C}$, the strong downward bend in the voltammograms for the $\mathrm{SmMnO}_{3+\delta}$ and $\mathrm{GdMnO}_{3+\delta}$ perovskites, also observed in the oxygencontaining atmosphere, at low potentials is seen again.

The maximum cathodic current density obtained is given in Table 2. It is observed that the apparent selectivity is highest for the La compound.

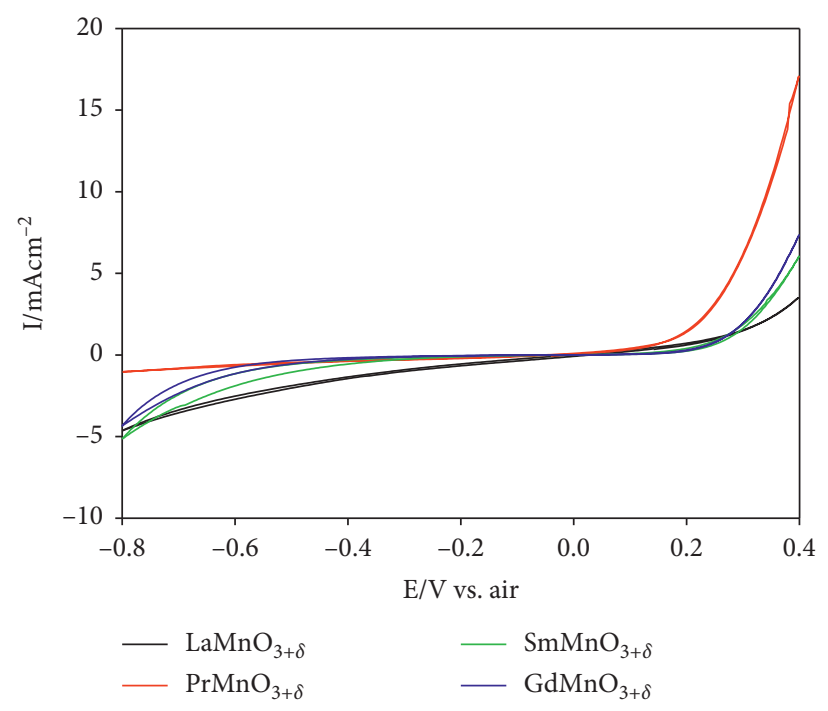

Figure 4: The voltammograms recorded on the four manganitebased perovskite with different A-site cations in an atmosphere with $10 \% \mathrm{O}_{2}$ in $\mathrm{Ar}$ at $400 \mathrm{C}$ with a sweep rate of $1 \mathrm{mV} / \mathrm{s}$. At this temperature, only little difference is observed in the cathodic region. However, in the anodic region, where oxygen is evolved, the $\mathrm{PrMnO}_{3+\delta}$ perovskite has a much higher activity than the other three perovskites.

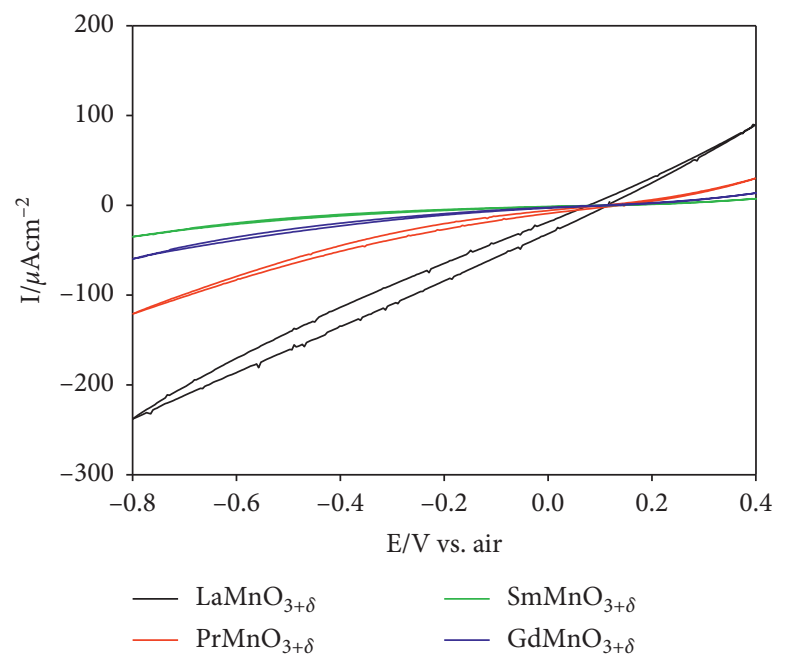

FIGURE 5: The response in the form of voltammograms from the four manganite-based perovskite-based cone-shaped electrodes in $1 \% \mathrm{NO}$ in $\mathrm{Ar}$ at $200 \mathrm{C}$ with a sweep rate of $1 \mathrm{mV} / \mathrm{s}$. A large difference is observed between the four manganite-based perovskites. The $\mathrm{LaMnO}_{3+\delta}$ perovskite is by the far the most active. The activities of the $\mathrm{SmMnO}_{3+\delta}$ and $\mathrm{GdMnO}_{3+\delta}$ perovskites are almost identical.

The activation energies are given in Table 3. The activation energy is highest for the $\mathrm{LaMnO}_{3+\delta}$ perovskite in the oxygen-containing atmosphere, $0.87 \mathrm{eV}$. This compound also has the lowest activation energy, $0.37 \mathrm{eV}$, in the nitric oxide-containing atmosphere. For the $\mathrm{SmMnO}_{3+\delta}$ and $\mathrm{GdMnO}_{3+\delta}$ perovskites, the activation energy is almost the same, around $0.65 \mathrm{eV}$, in the oxygen- and nitric oxide- 


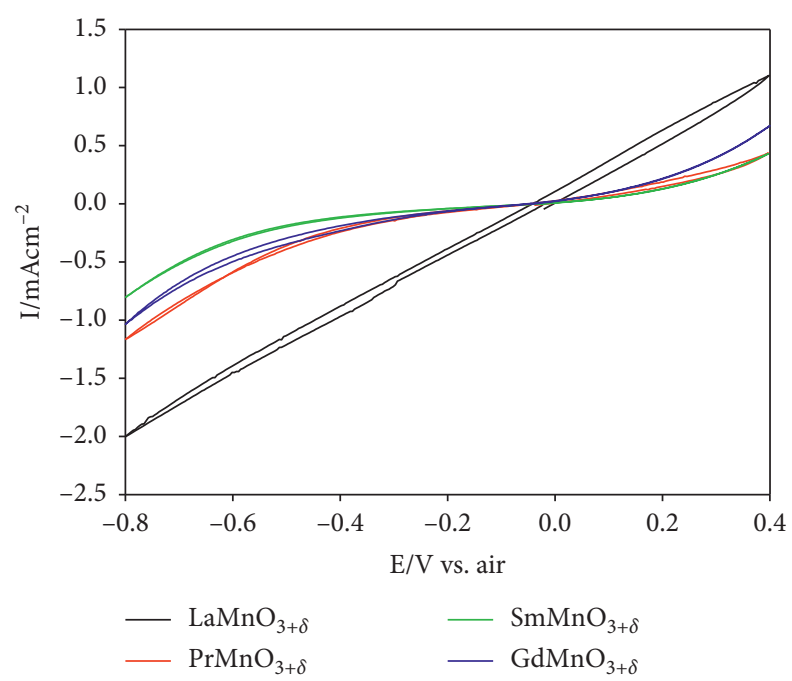

Figure 6: Voltammograms recorded at $300 \mathrm{C}$ in $1 \% \mathrm{NO}$ in $\mathrm{Ar}$ on the four manganite-based perovskites with different A-site cations. The voltammograms are recorded with a sweep rate of $1 \mathrm{mV} / \mathrm{s}$. Also at this temperature, the $\mathrm{LaMnO}_{3+\delta}$ perovskite is the most active. The differences between the three other manganite-based perovskites are smaller at this temperature.

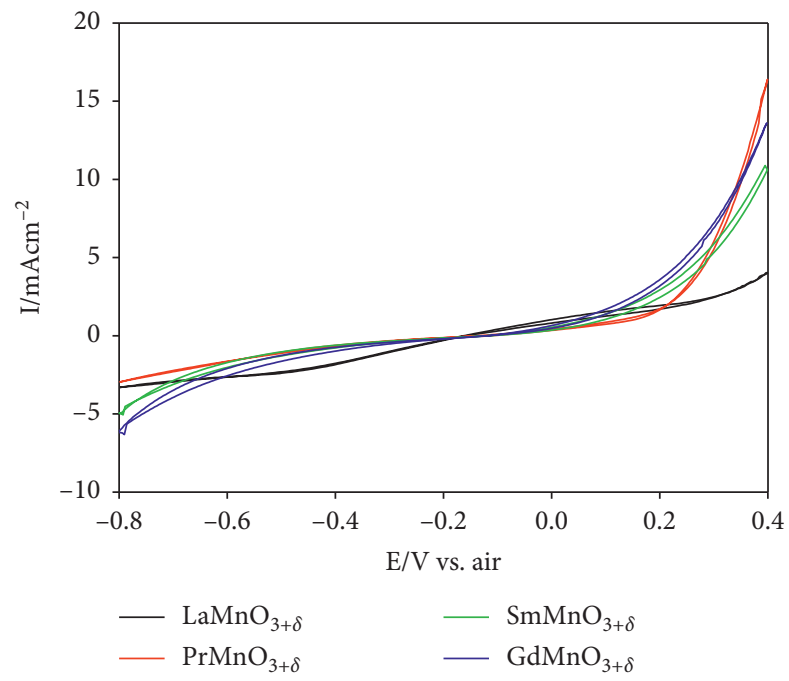

Figure 7: At 400 C, the voltammograms recorded on the four manganite-based perovskites in $1 \%$ NO in Ar are becoming more similar. The voltammograms are recorded with a sweep rate of $1 \mathrm{mV} / \mathrm{s}$. It is noteworthy that the downward bend of the voltammograms recorded on the $\mathrm{SmMnO}_{3+\delta}$ and $\mathrm{GdMnO}_{3+\delta}$ perovskites at low potentials is more pronounced than that on the $\mathrm{LaMnO}_{3+\delta}$ and $\mathrm{PrMnO}_{3+\delta}$ perovskites.

TABLE 2: Maximum cathodic current densities in oxygen- and nitric oxide-containing atmospheres for the four manganite-based perovskites, given in $\mathrm{mA} / \mathrm{cm}^{2}$. The current densities increase with increasing temperature. The apparent selectivity for the reduction of nitric oxide is highest for the $\mathrm{LaMnO}_{3+\delta}$ perovskite at $200^{\circ} \mathrm{C}$.

\begin{tabular}{lcccccrrr}
\hline Compound & \multicolumn{2}{c}{$\mathrm{LaMnO}_{3+\delta}$} & \multicolumn{2}{c}{$\mathrm{PrMnO}_{3+\delta}$} & \multicolumn{2}{c}{$\mathrm{SmMnO}_{3+\delta}$} & \multicolumn{2}{c}{$\mathrm{GdMnO}_{3+\delta}$} \\
$\mathrm{T} /$ gas & $\mathrm{O}_{2}$ & $\mathrm{NO}$ & $\mathrm{O}_{2}$ & $\mathrm{NO}$ & $\mathrm{O}_{2}$ & $\mathrm{NO}$ & $\mathrm{O}_{2}$ \\
\hline $200^{\circ} \mathrm{C}$ & 0.01 & 0.23 & 0.01 & 0.12 & 0.04 & 0.04 & 0.04 \\
$300^{\circ} \mathrm{C}$ & 2.60 & 2.00 & 0.20 & 1.20 & 1.00 & 0.80 & 1.00 \\
$400^{\circ} \mathrm{C}$ & 4.60 & 3.20 & 1.00 & 3.00 & 4.50 & 5.00 & 4.50 & 6.06 \\
\hline
\end{tabular}

TABle 3: The activation energies for the reduction of oxygen and nitric oxide in the temperature interval 200 to $400^{\circ} \mathrm{C}$ given in eV. The activation energy is highest for the end member $\mathrm{LaMnO}_{3+\mathrm{d}}$ in the oxygen-containing atmosphere. The activation energies in the oxygencontaining atmospheres are almost the same for the three other manganite-based perovskites.

\begin{tabular}{lcccccrrr}
\hline Compound & \multicolumn{2}{c}{$\mathrm{LaMnO}_{3+\delta}$} & \multicolumn{2}{c}{$\mathrm{PrMnO}_{3+\delta}$} & \multicolumn{2}{c}{$\mathrm{SmMnO}_{3+\delta}$} & \multicolumn{2}{c}{$\mathrm{GdMnO}_{3+\delta}$} \\
Gas & $\mathrm{O}_{2}$ & $\mathrm{NO}$ & $\mathrm{O}_{2}$ & $\mathrm{NO}$ & $\mathrm{O}_{2}$ & $\mathrm{NO}$ & $\mathrm{O}_{2}$ & $\mathrm{NO}$ \\
\hline$E_{\mathrm{A}}$ & 0.87 & 0.37 & 0.64 & 0.45 & 0.65 & 0.66 & 0.65 \\
\hline
\end{tabular}


containing atmospheres. The activation energy in the oxygen-containing atmosphere for the $\mathrm{PrMnO}_{3+\delta}$ perovskite is similar to the activation energies of the $\mathrm{SmMnO}_{3+\delta}$ and $\mathrm{GdMnO}_{3+\delta}$ perovskites. However, the activation energy for the $\mathrm{PrMnO}_{3+\delta}$ perovskite, in the nitric oxide-containing atmosphere, is markedly lower than the activation energies for the $\mathrm{SmMnO}_{3+\delta}$ and $\mathrm{GdMnO}_{3+\delta}$ perovskites. The differences in activation energies make the $\mathrm{LaMnO}_{3+\delta}$ and $\mathrm{PrMnO}_{3+\delta}$ perovskites the ones with the highest apparent selectivity towards the reduction of nitric oxide at the lowest temperatures.

\section{Discussion}

The crystal structures obtained for the four different perovskites with different A-site cations are in accordance with the literature [16-18]. The distortion of the ideal cubic perovskite structure, seen in this study, will normally lead to a lowering of the electronic conductivity, when the size of the A-site cation is lowered. This is due to less overlap between the p-orbitals from the oxygen and the d-orbitals from the B-site cation, the so-called superexchange. However, probably the effect is so small and has no practical importance for the use of the manganite-based perovskites as electrodes.

In the following tentative explanations, the differences in the electrochemical behavior of the four perovskites will be given. For the reduction of oxygen, the $\mathrm{PrMnO}_{3+\delta}$ perovskite always shows the lowest activity, in the investigated temperature range. This is in contradiction with the literature [11], but it should be kept in mind that this study has been undertaken at much lower temperatures than that in the literature and that the manganites investigated in the literature were strontium doped. The reason for the low activity of the Pr-containing manganite could be because the Pr can exist also in the oxidation state $\operatorname{Pr}(\mathrm{IV})$, leading to a higher concentration of cation vacancies in the perovskite structure. The behavior of the $\mathrm{LaMnO}_{3+\delta}$ perovskites is very different than that of the other perovskites. This could be due to that the mobility of oxide ions is more thermally activated on the $\mathrm{LaMnO}_{3+\delta}$ perovskite than on the other perovskites. That the voltammograms for the $\mathrm{SmMnO}_{3+\delta}$ and $\mathrm{GdMnO}_{3+\delta}$ perovskites bend more strongly downwards at low potentials could be because these two perovskites are easier to reduce than the $\mathrm{LaMnO}_{3+\delta}$ and $\mathrm{PrMnO}_{3+\delta}$ perovskites (see [19]), leading to the creation of oxide ion vacancies in perovskite structure at low oxygen partial pressures (low potentials). This can be explained on the background of the inductive effect. When the size of the A-site cation is lowered, the A-site cation will attract more electron density from oxygen. This will again make oxygen attracting more electron density from the B-site cation, lowering the electron density on the B-site cation. This will make it easier to reduce the B-site cation, as observed in this study.

The differences of the manganite-based perovskite cathodes are larger at the lowest temperature also in the nitric oxide-containing atmosphere, and the differences level out at the highest temperature (see Table 2). The nitric oxide is perhaps bound more strongly on the $\mathrm{LaMnO}_{3+\delta}$ and
$\mathrm{PrMnO}_{3+\delta}$ perovskites at the lowest temperatures. That the activity increases less with increasing temperature for the $\mathrm{LaMnO}_{3+\delta}$ and $\mathrm{PrMnO}_{3+\delta}$ perovskites could also be due to weak chemisorption of nitric oxide on these compounds at elevated temperature. It has been shown in the literature that oxygen is bound less strongly on these compounds than on $\mathrm{GdMnO}_{3+\delta}[19]$. At $400^{\circ} \mathrm{C}$, the same trends as in the oxygencontaining atmosphere are observed, that is, the reduction of the perovskites at low applied potentials is easier when the size of the A-site cation is lowered.

For the oxygen evolution, the $\mathrm{PrMnO}_{3+\delta}$ perovskite shows superior activity at $400^{\circ} \mathrm{C}$. Pr-containing compounds have before been shown to be good catalysts for oxidation processes [20]. The activity of the $\mathrm{PrMnO}_{3+\delta}$ perovskite for oxidizing nitric oxide to nitrogen dioxide is also highest at $400^{\circ} \mathrm{C}$, even though the effect is much less pronounced than in the oxygen-containing atmosphere.

That the activation energies are almost the same on $\mathrm{PrMnO}_{3+\delta}, \mathrm{SmMnO}_{3+\delta}$ and $\mathrm{GdMnO}_{3+\delta}$ perovskites in the oxygen-containing atmosphere indicates that the reaction mechanism is the same for these three manganite-based perovskites. However, for the $\mathrm{LaMnO}_{3+\delta}$ perovskite, the higher activation energy suggests that the reduction of oxygen takes place through a different mechanism than on the three other perovskites. In the nitric oxide-containing atmosphere, the activation energies suggest that the reduction of nitric oxide proceeds through different mechanisms for the $\mathrm{LaMnO}_{3+\delta}$ and $\mathrm{PrMnO}_{3+\delta}$ perovskites and for the $\mathrm{SmMnO}_{3+\delta}$ and $\mathrm{GdMnO}_{3+\delta}$ perovskites.

\section{Conclusion}

Four manganite-based perovskites, $\mathrm{LaMnO}_{3+\delta}, \mathrm{PrMnO}_{3+\delta}$, $\mathrm{SmMnO}_{3+\delta}$, and $\mathrm{GdMnO}_{3+\delta}$ perovskites, were synthesized and shown to be single phased by powder XRD. The manganites were shown to be better at reducing nitric oxide than oxygen at the lowest temperature. At higher temperatures, the differences leveled out. The work clearly revealed that the choice of the A-site cation is important when designing electrodes for electrochemical reduction of oxygen or nitric oxide at low temperatures. The differences in the activity of then manganites were tentatively explained on the background of the inductive effect, chemisorption, and the oxide ion mobility in the crystal lattice.

\section{Data Availability}

All data will be available on request.

\section{Conflicts of Interest}

The authors declare that they have no conflicts of interest.

\section{References}

[1] G. C. Koltsakis and A. M. Stamatelos, "Catalytic automotive exhaust after treatment," Progress in Energy and Combustion Science, vol. 23, p. 1, 1997. 
[2] K. C. Taylor, Frontiers of Materials Research/Electronic and Optical Materials, M. Kong and L. Huang, Eds., pp. 46-56, Elsevier, Amsterdam, Netherlands, 1991.

[3] J. Kaspar, P. Fornasiero, and N. Hickey, "Automotive catalytic converters: current status and some perspectives," Catalysis Today, vol. 77, p. 419, 2003.

[4] H. Bosch and F. Janssen, "Preface," Catalysis Today, vol. 2, p. 369, 1988.

[5] S. Pancharatnam, R. A. Huggins, and D. M. Mason, "Catalytic decomposition of nitric oxide on zirconia by electrolytic removal of oxygen," Journal of The Electrochemical Society, vol. 122, no. 7, p. 869, 1975.

[6] K. K. Hansen, "Solid state electrochemical DeNOx-An overview," Applied Catalysis B: Environmental, vol. 100, no. 34, pp. 427-432, 2010.

[7] K. K. Hansen, E. M. Skou, and H. Christensen, "Perovskites as cathodes for nitric oxide reduction," Journal of The Electrochemical Society, vol. 147, no. 5, p. 2007, 2000.

[8] K. K. Hansen, H. Christensen, and E. M. Skou, "Electrochemical reduction of $\mathrm{NO}$ and $\mathrm{O}_{2}$ on oxide based electrodes," Ionics, vol. 6, no. 5-6, pp. 340-345, 2000.

[9] K. Kammer Hansen, "Electrochemical reduction of oxygen and nitric oxide at low temperature on $\mathrm{La} 1-\mathrm{xSrxMnO}_{3+\delta}$ cathodes," Materials Research Bulletin, vol. 48, no. 9, pp. 3274-3277, 2013.

[10] T. Ishihara, T. Kudo, H. Matsuda, and Y. Takita, "Doped perovskite oxide, $\mathrm{PrMnO}_{3}$, as a new cathode for solid-oxide fuel cells that decreases the operating temperature," Journal of the American Ceramic Society, vol. 77, p. 1686, 1994.

[11] T. Ishihara, T. Kudo, H. Matsuda, and Y. Takita, "Doped PrMnO[sub 3] perovskite oxide as a new cathode of solid oxide fuel cells for low temperature operation," Journal of The Electrochemical Society, vol. 142, no. 5, p. 1519, 1995.

[12] P. Fabry and M. Kleitz, "Influence of the metal and the electrolyte composition on the characteristics of the oxygen electrode reaction on solid oxide electrolyte," Journal of Electroanalytical Chemistry and Interfacial Electrochemistry, vol. 57, no. 2, pp. 165-177, 1974.

[13] L. A. Chick, L. R. Pederson, G. D. Maupin, J. L. Bates, L. E. Thomas, and G. J. Exarhos, "Glycine-nitrate combustion synthesis of oxide ceramic powders," Materials Letters, vol. 10, no. 1-2, pp. 6-12, 1990.

[14] K. K. Hansen, H. Christensen, E. M. Skou, and S. V. Skaarup, "Electrochemical reduction of $\mathrm{NO}$ and $\mathrm{O}_{2}$ on $\mathrm{Cu} / \mathrm{CuO}$," Journal of Applied Electrochemistry, vol. 30, no. 2, pp. 193-200, 2000.

[15] J. Newman, "Resistance for flow of current to a disk," Journal of The Electrochemical Society, vol. 113, no. 5, p. 501, 1966.

[16] J. A. M. Roosmalen, E. H. P. Cordfunke, R. B. Helmholdt, and H. W. Zandbergen, "Electrical conductivity in La1-xSrxMnO${ }_{3+\delta}$, Journal of Solid State Chemistry, vol. 110, p. 100, 1994.

[17] Z. Jirák, J. Hejtmánek, K. Knížek, and R. Sonntag, "Structure and Properties of the $\operatorname{Pr} 1-\mathrm{xKxMnO}$ Perovskites $(\mathrm{x}=0-0.15)$," Journal of Solid State Chemistry, vol. 132, no. 1, pp. 98-106, 1997.

[18] T. Mori, N. Kamegashira, K. Aoki, T. Shishido, and T. Fukuda, "Crystal growth and crystal structures of the $\mathrm{LnMnO}_{3}$ perovskites: $\mathrm{Ln}=\mathrm{Nd}, \mathrm{Sm}, \mathrm{Eu}$ and Gd," Materials Letters, vol. 54, no. 2-3, pp. 238-243, 2002.

[19] P. E. Marti and A. Baiker, "Influence of the A-site cation in $\mathrm{AMnO}_{3+\mathrm{x}}$ and $\mathrm{AFeO}_{3+\mathrm{x}}(\mathrm{A}=\mathrm{La}, \mathrm{Pr}, \mathrm{Nd}$ and $\mathrm{Gd})$ perovskitetype oxides on the catalytic activity for methane combustion," Catalysis Letters, vol. 26, no. 1-2, pp. 71-84, 1994.
[20] D. Ippolito and K. K. Hansen, "Effect of infiltration material on a LSM15/CGO10 electrochemical reactor in the electrochemical oxidation of propene," Journal of Solid State Electrochemistry, vol. 17, no. 3, pp. 895-908, 2013. 